\title{
The Role of the SLC Transporters Protein in the Neurodegenerative Disorders
}

\author{
Asli Aykaç ${ }^{1}$, Ahmet Özer Şehirli ${ }^{2}$ \\ ${ }^{1}$ Department of Biophysics, Faculty of Medicine and ${ }^{2}$ Department of Pharmacology, Faculty of Dentistry, Near East University, Nicosia, Cyprus
}

\begin{abstract}
The solute carrier (SLC) superfamily is one of the major sub-groups of membrane proteins in mammalian cells. The solute carrier proteins include more than 400 different membrane-spanning solute carriers organized with 65 families in the human. In solute carrier family neurons, neurotransmitter is considered to be a pharmacological target of neuropsychiatric drugs because of their important role in the recovery of neurotransmitters such as GABA, glutamate, serotonin, dopamine and noradrenaline and regulation of their concentration in synaptic regions. Therefore, solute carrier transporters play vital and different roles in neurodegenerative disorders. In this article, the role of solute carrier transporters in neurodegenerative disorders such as Alzheimer disease, amyotrophic lateral sclerosis, Huntington disease, Parkinson's diseases, depression, post-traumatic stress disorder, dementia, schizophrenia, and Epilepsy reviewed and discussed to see how defects or absences in SLC transporter cause neurodegenerative disorders. In this review, we try to summarize what is known about solute carriers with respect to brain distribution and expression. The review summarizes current knowledge on the roles of solute carrier transporters in neurodegenerative disorders.
\end{abstract}

KEY WORDS: Solute carrier; Amyotrophic lateral sclerosis; Alzheimer disease; Post-traumatic stress disorder; Depression.

\section{INTRODUCTION}

Genes encoding the membrane protein, one of the largest gene groups in human and mouse genome, are claimed to be more than $10 \%$ of genes encoding all genes [1] Solute carriers (SLCs) proteins, one of the major subgroups of membrane proteins that control the transport of exceptional substances such as sugar, amino acids, nucleotides, inorganic ions, lipids, and drugs on the cell membrane, include more than 400 different membranespanning SLCs organized with 65 families in the human [2]. Many of these membrane proteins act as coupled symporters (co-transporters) using downhill ion $\left(\mathrm{H}^{+}\right.$or $\left.\mathrm{Na}^{+}\right)$ gradients as a pushing force to transport the substrate to cells against the concentration gradient [3].

The transported molecule moves towards the low con-

Received: October 7, 2019/ Revised: October 25, 2019

Accepted: November 6, 2019

Address for correspondence: Ahmet Özer Şehirli

Department of Pharmacology, Faculty of Dentistry, Near East

University, Near East Boulevard, Nicosia 99138, Cyprus

E-mail: ahmetozer.sehirli@neu.edu.tr

ORCID: https://orcid.org/0000-0002-8075-3672 centration region through the membrane and reaches equilibrium. Other members of the SLC family function as antiporters with substrate-binding sites, while the remaining members show channel-like properties. It is known that ion exchangers cause $\mathrm{pH}$ alterations around the cell surface. Therefore, when combined with $\mathrm{Na}^{+} / \mathrm{K}^{+}$ATPase, they negate the load balance by making the intracellular membrane potentially negative. The transition of the molecule through membranes is facilitated either by changing load balance or $\mathrm{pH}$ [4]. In SLC family neurons, the neurotransmitter is considered to be neurodegenerative disorders such as schizophrenia (GABA, GLYT, and SERT), epilepsy (GABA and BGT), anxiety (GABA and SERT), depression (SERT and NAT), and Parkinson disease (DAT), amyotrophic lateral sclerosis (GLT) [5]. In particular, irregularities in SLC polymorphism play role in the mechanism of neurological and neuropsychiatric disorders by altering transport expression, malfunction, and regulation in the neurotransmitter system (Fig. 1).

(c) This is an Open-Access article distributed under the terms of the Creative Commons Attribution Non-Commercial License (http://creativecommons.org/licenses/by-nc/4.0) which permits unrestricted non-commercial use, distribution, and reproduction in any medium, provided the original work is properly cited. 


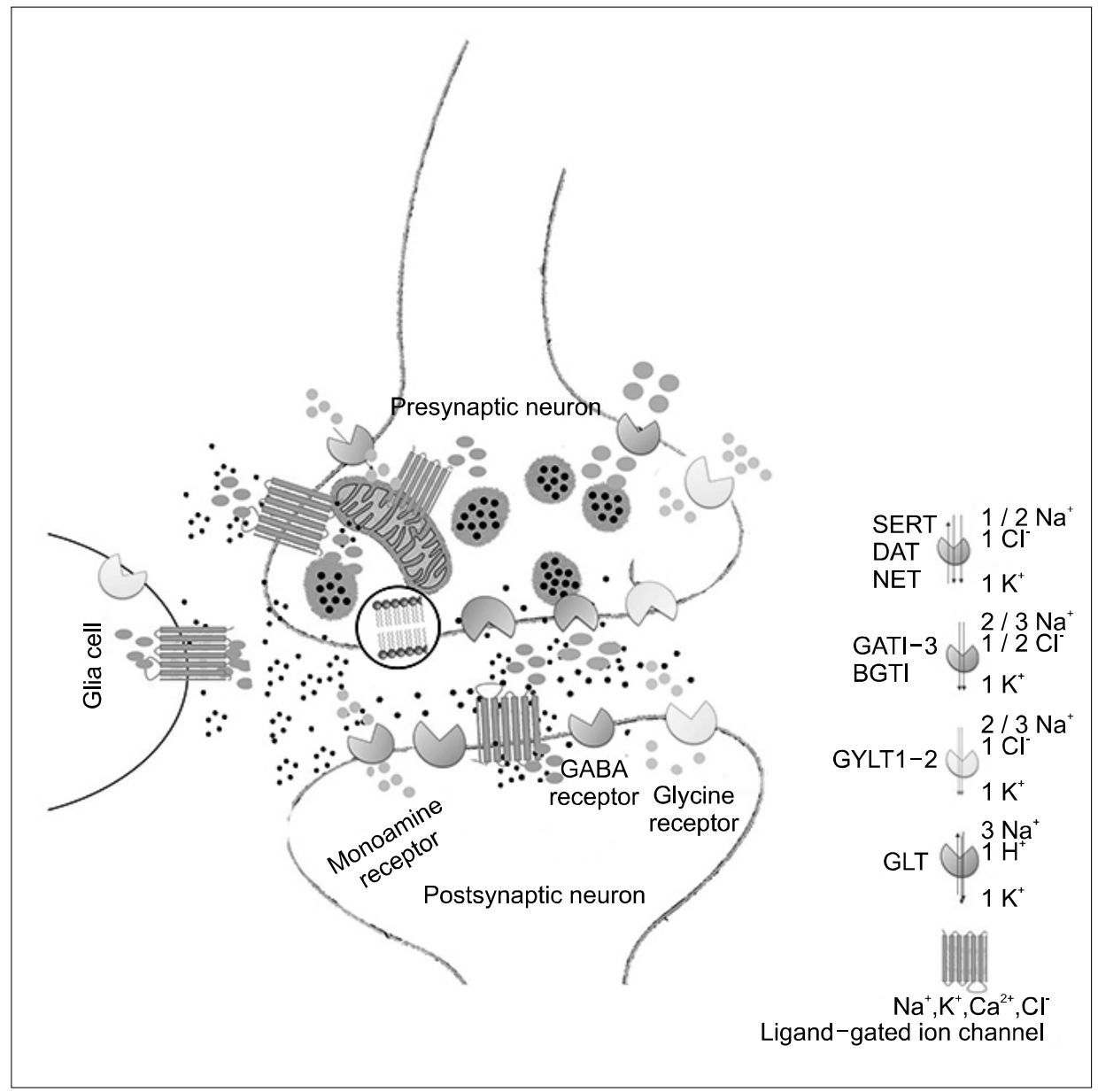

Fig. 1. A schematic representation of the physiologic function of solute carriers (SLCs) and their role in synaptic transmission in the central nervous system. SLC transporters are critical in the termination of synaptic transmission for amino acid neurotransmitters in addition to their role in providing essential nutrients and osmolytes to neurons and glial cells. Dopamine, serotonin, noradrenaline, glycine, and GABA are removed by neurotransmitter sodium symporters. The monoamine transporters (NET, SERT, and DAT) are localized to extra-synaptic sites, whereas GATs, GLYTs, and osmolyte transporter (BGTs), are localized to synaptic and extra-synaptic sites in addition to glial cells. Inhibition of NET, SERT, and DAT transporters by drugs reduces the clearance of neurotransmitters from the synapse, thus increasing their stay time in the synaptic cleft. The resulting increased concentrations of monoamines in the synaptic cleft improve receptor occupancy, leading to increased activation of ligand-gated ion channels. GLTs play a major role in maintaining the extracellular glutamate concentration at low levels and to protect neurons from the excitotoxic action of glutamate. Due to their crucial role in keeping basal concentrations of neurotransmitters low, malfunction, improper, or dysfunction of these transporters may lead to developing neurodegenerative disorders.

Neurotransmitter transporters (GAT [ $\gamma$-aminobutyric acid], GYLT [glycine], and monoamine trasporter DAT [dopamine], NET [noradrenaline], SERT [serotonin]). Osmolyte transporter, BGT (betaine). Neutral amino acid transporter, GLT (glutamate).

\section{SOLUTE CARIERS' TRANSPORTER FAMILY}

The localization of SLC proteins in the brain is shown in Table 1. neurotransmitters in the brain that are released into the synapse are taken back to presynaptic neurons via SLC1 and 6 carriers [2]. SLC1 family has two subfamilies that encode glutamate transporters (SLC1A1, 2, 3, 6, and k) and neutral aminoacid transporters (SLC1A4 and 5). SLC2 members like 1, 2, 3, 6, 8, 10, and 13 are expressed in the brain. SLC5 human genes encoding SGLT proteins with the exception of SLC5A4, 5, and 7 are all expressed in the brain [6,7]. SLCA1-7 human genes are members of the high-affinity glutamate and neutral amino acid transporter family. SLC1A5 and 7 are known not to show any expression in the human brain. SLC1A1 encodes glutamate carrier called EAAC1 (also known as EAAT3). EAAC1 is a neuronal type-high affinity glutamate carrier. They are predominantly expressed in neurons in various brain regions, particularly in the hippocampus, cerebral cortex, striatum, superior colliculus, and thalamus [8]. 
Table 1. The distribution of solute carrier (SLC) proteins in the brain and the disorders in which play a role

\begin{tabular}{|c|c|c|c|}
\hline Gene name & Protein name & Brain tissue expression & Disorders \\
\hline SLC1 & & & $\begin{array}{l}\text { HD, epilepsy, AD, ALS, schizophrenia [3], } \\
\text { dementia }\end{array}$ \\
\hline SLC1A1 & $\begin{array}{l}\text { EAAC1 } \\
\text { EAAT3 }\end{array}$ & Neurons [9] & HD, epilepsy, AD [9] \\
\hline SLC1A2 & $\begin{array}{l}\text { GLT1 } \\
\text { EAAT2 }\end{array}$ & Astrocytes [9] & $\mathrm{AD}, \mathrm{PD}, \mathrm{ALS}[9]$, dementia \\
\hline SLC1A3 & $\begin{array}{l}\text { GLAST } \\
\text { EAAT1 }\end{array}$ & Astrocytes, cerebellar Bergmann glia [9] & AD, HD, ALS, epilepsy [9] \\
\hline SLC1A4 & $\begin{array}{l}\text { ASCT1 } \\
\text { SATT }\end{array}$ & Neurons & \\
\hline SLC1A5 & $\begin{array}{l}\text { ASCT2 } \\
\text { AAAT }\end{array}$ & Neurons & \\
\hline SLC1A6 & EAAT4 & $\begin{array}{l}\text { Cerebellum (pukinje cells) on postsynaptic dendritis } \\
\text { spines [9] }\end{array}$ & \\
\hline SLC1A7 & EAAT5 & Retinal neurons & \\
\hline SLC2A4 & GLUT4 & Hippocampus, neurons & Stress [7] \\
\hline SLC5A1 & SGLT1 & Hypothalamic neurons in rat brain [82] & \\
\hline SLC5A2 & SGLT2 & Hypothalamic neurons in rat brain [82] & \\
\hline SLC5A3 & SMIT1 & Hypothalamic neurons in rat brain [82] & \\
\hline SLC5A6 & SMVT & Hypothalamic neurons in rat brain [82] & \\
\hline SLC5A8 & SMCT & Hypothalamic neurons in rat brain [82] & \\
\hline SLC5A9 & SGLT4 & Hypothalamic neurons in rat brain [82] & \\
\hline SLC5A10 & SGLT5 & Hypothalamic neurons in rat brain [82] & \\
\hline SLC5A11 & SMIT2 & Hypothalamic neurons in rat brain [82] & \\
\hline SLC5A12 & SMCT2 & Hypothalamic neurons in rat brain [82] & \\
\hline SLC5A4 & SGLT3 & $\begin{array}{l}\text { Cholinergic neurons in human brain and hypothalamic } \\
\text { neurons in rat brain [82] }\end{array}$ & \\
\hline SLC6 & & & Epilepsy [21], schizophrenia, depression [3] \\
\hline SLC6A1 & GAT1 & Brain & Epilepsy [21], schizophrenia [21], anxiety [82] \\
\hline SLC6A2 & NET & Non adrenergic neuronal somata, axons, dendrites & Depression [3,82] \\
\hline SLC6A3 & DAT & Dopaminergic neurons, & PD [21,82], PTSD [79], depression [3] \\
\hline SLC6A4 & SERT & Brain & Anxiety [82], depression [3] \\
\hline SLC6A5 & GLYT2 & Glycinergic neurons, Golgi cells, brainstem, cerebellum & Depression [3], schizophrenia [21] \\
\hline SLC6A6 & TAUT & Brain & \\
\hline SLC6A7 & PROT & Glutamatergic neurons, hippocampus & \\
\hline SLC6A8 & $\mathrm{CT} 1$ & Ubiquitous all tissues & \\
\hline SLC6A9 & GLYT1 & Brain & Schizophrenia [21,82], depression [3] \\
\hline SLC6A11 & GAT3 & Gabaergic neurons, glia & Epilepsy [21] \\
\hline SLC6A12 & BGT1 & Brain & Epilepsy [21] \\
\hline SLC6A13 & GAT2 & Meninges, ependyma, choroid plexus & Epilepsy [21] \\
\hline SLC6A15 & & $\begin{array}{l}\text { Amygdala, putamen, corpus callosum in human brain and } \\
\text { hippocampus in rat brain }\end{array}$ & Stress [78], depression \\
\hline SLC6A17 & & Brain & \\
\hline SLC6A20 & & Brain & \\
\hline SLC7A3 & CAT3 & Neurons [22] & \\
\hline SLC7A4 & CAT4 & Brain [22] & \\
\hline SLC7A5 & LAT2 & Brain [22] & \\
\hline SLC7A6 & yLAT & Brain [22] & \\
\hline SLC7A8 & LAT2 & Brain [22] & \\
\hline SLC7A10 & ASC1 & Brain [22] & \\
\hline SLC7A11 & $\mathrm{xCT}$ & Brain [22] & \\
\hline SLC8A1 & NCX1 & Specific splice variants found in brain & \\
\hline SLC8A2 & NCX2 & Abundant in neurons in all parts of the brain & \\
\hline SLC8A3 & NCX3 & At lower levels in some brain regions & \\
\hline
\end{tabular}


Table 1. Continued 1

\begin{tabular}{|c|c|c|c|}
\hline Gene name & Protein name & Brain tissue expression & Disorders \\
\hline SLC10A4 & P4 & Cholinergic neurons & AD, epilepsy [3] \\
\hline SLC11A1 & NRAMP1 & & $\mathrm{AD}, \mathrm{PD}[3]$ \\
\hline $\mathrm{SLC} 11 \mathrm{~A} 2$ & DMT1 & & PD [3] \\
\hline SLC12A2 & NKCC1 & Ubiquitous in all tissues [28] & Epilepsy [3], HD \\
\hline SLC12A4 & KCC1 & Ubiquitous in all tissues [28] & \\
\hline SLC12A5 & KCC2 & Neurons [28] & Epilepsy [3], HD \\
\hline SLC12A7 & KCC4 & Extensive limited in brain [28] & Epilepsy [3] \\
\hline SLC13A3 & $\mathrm{NaC} 3$ & Brain & \\
\hline SLC13A5 & $\mathrm{NaC} 2$ & Brain & \\
\hline SLC15A3 & PHT2 & Brain & \\
\hline SLC15A4 & PHT1 & Brain & \\
\hline SLC16A2 & МСТ8 & Brain & \\
\hline SLC16A5 & MCT6 & Brain & \\
\hline SLC16A7 & МCT2 & Brain & \\
\hline SLC16A9 & МСТ9 & Brain & \\
\hline SLC16A14 & MCT14 & Brain & \\
\hline SLC17A2 & NPT3 & Brain & \\
\hline SLC17A6 & VGLUT2 & Neurons & \\
\hline SLC17A7 & VGLUT1 & Neurons & \\
\hline SLC17A8 & VGLUT3 & Neurons, glia & \\
\hline SLC17A9 & VNUT & Neurons & \\
\hline SLC18A2 & VMAT2 & All CNS aminergic neurons & \\
\hline SLC18A3 & VAChT & Cholinergic neurons & \\
\hline SLC18B1 & C6orf192 & Brain & \\
\hline SLCO1A2 & OATP1A2 & Brain & \\
\hline SLCO1C1 & OATP1C1 & Blood-brain barrier & \\
\hline SLC22A1 & OCT1 & Blood-brain barrier & \\
\hline SLC22A2 & ОСТ2 & Blood-brain barrier, neurons & \\
\hline SLC22A3 & ОСТ3 & Neurons, glial cells, plexus choroideus & \\
\hline SLC22A15 & FLIPT1 & Brain & \\
\hline SLC22A17 & BOIT & Brain & \\
\hline SLC22B1 & SV2A & Subcortex (basal ganglia, thalamus) & \\
\hline SLC22B2 & SV2B & Hippocampus, cortex & \\
\hline SLC22B3 & SV2C & $\begin{array}{l}\text { Striatum, substantia nigra, pons/medulla oblongata, } \\
\text { olfactory bulb }\end{array}$ & \\
\hline SLC22B4 & SVOP & Brain & \\
\hline SLC22B 5 & SVOPL & Brain & \\
\hline SLC23A2 & SVCT2 & Neurons & \\
\hline SLC24A2 & NCKX2 & Brain & \\
\hline SLC24A3 & NCKX3 & Brain & \\
\hline SLC24A4 & NCKX4 & Brain & \\
\hline SLC25 & & & Epileptic encephalopathy [3] \\
\hline SLC25A2 & $\mathrm{ORC}^{\mathrm{a}}$ & Brain & \\
\hline SLC25A3 & $\mathrm{PHC}$ & Brain & \\
\hline SLC25A4 & ANT1 & Brain & \\
\hline SLC25A5 & ANT2 & Brain & \\
\hline SLC25A6 & ANT3 & Brain & \\
\hline SLC25A8 & UCP2 & Hypothalamus, pituitary, brainstem [33] & \\
\hline SLC25A10 & DIC & & \\
\hline SLC25A12 & AGC1 & & \\
\hline SLC25A14 & $\begin{array}{l}\text { UCP5 } \\
\text { BMCP1 }\end{array}$ & $\begin{array}{l}\text { Hypothalamus, hippocampus, thalamus, amygdale in the } \\
\text { mice brain [33] }\end{array}$ & \\
\hline SLC25A15 & ORC1 & Brain & \\
\hline
\end{tabular}


Table 1. Continued 2

\begin{tabular}{|c|c|c|c|}
\hline Gene name & Protein name & Brain tissue expression & Disorders \\
\hline & & Brain & \\
\hline SLC25A18 & GC2 & Brain & \\
\hline SLC25A19 & DNC & Brain & \\
\hline SLC25A20 & CAC & Brain & ALS \\
\hline SLC25A22 & GC1 & Brain & \\
\hline SLC25A23 & APC2 & Brain & \\
\hline SLC25A25 & APC3 & Brain & \\
\hline SLC25A27 & UCP4 & Brain & \\
\hline SLC25A33 & & $\begin{array}{l}\text { Brainstem, thalamus, corpus callosum, hippocampus } \\
\text { brainstem, thalamus in the rat brain [33] }\end{array}$ & \\
\hline SLC25A40 & & $\begin{array}{l}\text { Cerebellum, olfactory bulb, cerebral cortex, midbrain, } \\
\text { pons [33] }\end{array}$ & \\
\hline SLC25A41 & APC4 & Olfactory bulb, pons, midbrain, cerebellum [33] & \\
\hline SLC25A42 & & Pons, midbrain, thalamus [33] & \\
\hline SLC25A44 & & $\begin{array}{l}\text { Hindbrain, cerebellum, pons, midbrain, hypothalamus, } \\
\text { corpus callosum [33] }\end{array}$ & \\
\hline SLC25A46 & & $\begin{array}{l}\text { Hindbrain, cerebellum, pons, midbrain, hypothalamus, } \\
\text { corpus callosum [33] }\end{array}$ & \\
\hline SLC26A9 & SLC26A9 & Brain & \\
\hline SLC26A11 & SUT1 & Brain & \\
\hline SLC27A1 & FATP1 & Brain & \\
\hline SLC27A4 & FATP4 & Brain & \\
\hline SLC28A2 & CNT2 & Brain & \\
\hline SLC29A4 & ENT4 & Brain & \\
\hline SLC30A3 & & Brain & \\
\hline SLC30A4 & & Brain & \\
\hline SLC30A10 & & Brain & Dementia [5,48], PD, AD [16] \\
\hline SLC31 & & Brain & Degenerative neuronal disease [3] \\
\hline SLC33A1 & CTR1 & Brain & \\
\hline SLC35F3 & & Cerebellum & \\
\hline SLC35F4 & & Cerebellum & \\
\hline SLC36A1 & PAT1 & Brain & \\
\hline SLC37A3 & SPX3 & Brain & \\
\hline SLC38A1 & SNAT1 & Brain & \\
\hline SLC38A4 & SNAT4 & Brain & \\
\hline SLC38A5 & SNAT5 & Brain & \\
\hline SLC38A6 & SNAT6 & Brain & \\
\hline SLC38A7 & SNAT7 & Brain & \\
\hline SLC38A8 & SNAT8 & Brain & \\
\hline SLC38A10 & $\mathrm{N} / \mathrm{A}$ & Brain & \\
\hline SLC39 & & & Neurodegeneration [3], PD, AD \\
\hline SLC39A4 & ZIP4 & Hippocampus, neurons & \\
\hline SLC39A10 & ZIP10 & Brain & \\
\hline SLC39A12 & ZIP1 & Brain & \\
\hline SLC40A1 & FPN1 & & $\mathrm{PD}$ \\
\hline SCL41A2 & RhBG & Cerebellum & $\mathrm{PD}$ \\
\hline SLC44A1 & CTL1 & Brain & \\
\hline SLC44A5 & CTL5 & Brain & \\
\hline SLC45A1 & SLC45A1 & Brain & \\
\hline SLC45A4 & SLC45A4 & Brain & \\
\hline SLC49A1 & FLVCR1 & Brain & \\
\hline SLC49A2 & FLVCR2 & Brain & \\
\hline SLC49A3 & MFSD7 & Brain & \\
\hline SLC52A2 & & Brain & \\
\hline
\end{tabular}


Table 1. Continued 3

\begin{tabular}{|c|c|c|c|}
\hline Gene name & Protein name & Brain tissue expression & Disorders \\
\hline SLC56A4 & SFXN4 & Brain & \\
\hline SLC56A5 & SFXN5 & Brain & \\
\hline SLC57 & & Brain & ALS [3] \\
\hline SLC57A1 & NIPA1 & Brain & \\
\hline SLC59A1 & MFSD2A & Brain & \\
\hline SLC60A2 & MFSD4B & Brain & \\
\hline SLC61A1 & NPC1 & Cortex, hypothalamus, cerebellum & \\
\hline
\end{tabular}

EAAC, excitatory amino acid carrier; EAAT, excitatory amino acid transporter; ASCT, amino acid transporter; DAT, dopamine transporter; PHT, phosphate transporter; GAT, GABA transporter; GLT, glutamate transporter; GLYT, glycine transporters; MCT, monocarboxylate transporter; NCX, $\mathrm{Na}^{+} / \mathrm{Ca}^{2+}$; NET, noradrenaline transporter; NRAMP, natural resistance-associated macrophage protein; OATP, organic anion transporter; SERT, serotonin transporter; SGLT, sodium glucose cotransporter 2 (SGLT-2); Zip, zinc transporter; ALS, amyotrophic lateral sclerosis; PD, Parkinson's disease; HD, Huntington disease; AD, Alzheimer disease.

Empty areas show that there is no study about the SCL protein.

${ }^{a}$ Ornithine carrier.

Studies on EAAC1 knock-out mice showed no improvement in neurological symptoms and neurodegeneration [9]. Besides, significant low spontaneous locomotor activity was found in homozygous mutants of knock-out mice [9]. SLC1A2 encodes glial type-high affinity glutamate transporter which is called glial glutamate transporter and glutamate synthase (GLT1) (also known as an excitatory amino acid carrier, EAAT2). This multi-pass membrane protein is required to terminate the postsynaptic effect of glutamate by rapidly removing glutamate release from the synaptic cleft, as well as preserves glutamate concentrations below toxic concentrations to prevent neuronal damage [10]. EAAT2 is particularly expressed in the cortex, hippocampus, and astrocytes of various brain regions. In the histological analysis, GLT1 knock-out mice showed neuronal degeneration in the hippocampal CA1 region, indicating the neuroprotective role of GLT1 [9]. It has also been reported that GLT1 knock-out mice have similar behavioral patterns and dramatic fatal spontaneous epileptic seizures as $\mathrm{N}$-methyl-D-aspartate (NMDA)-induced seizures [11]. SLC1A3, also known as EAAT1, encodes glutamate GLAST. is a glial type-high affinity glutamate carrier which is especially seen in cerebellum [9]. While GLAST knock-out mice can coordinate simple movements, it is reported that in more difficult movement dysfunction occurs in parallel with the abnormality in cerebellum [9]. SLC1A4 encodes the $\mathrm{Na}^{+}$dependent neutral amino acid carrier ASCT1 (also known as SATT) [12,13]. In the brain, ASCT1 is preferably expressed in glial cells with L-serine biosynthetic enzyme 3-phosphoglycerate dehydrogenase. Therefore, large amounts of L-serine are synthesized and stored in glial cells. The L-serine release is achieved by changing the structure of the extracellular substrate due to alterations in ASCT1. This change assumes that neurons will meet their metabolic needs through the transport of small glial born neutral amino acids [14]. This change assumes that neurons will meet their metabolic needs through the transport of small glial born neutral amino acids. ASCT1 shows a broad expression in the brain. SLC1A5 encodes a second isoform of the ASC transport system called ASCT2 (also known as AAAT). ASCT2 carries glutamate with low affinity and ASCT2 mediated glutamate transport increases at low $\mathrm{pH}$ [15]. Similar to ASCT1, ASCT2 mediates $\mathrm{Na}^{+}$dependent mandatory substrate amino acid change [16]. SLC1A6 encodes the neuronal high-affinity glutamate transporter EAAT4, which is expressed in purkinje cells in the cerebellum, mainly on postsynaptic dendritic spines $[17,18]$. The SLC1A7 gene encodes the EAAT5 protein and the members of the SLC4 family such as $3,4,7,8$, and 10 are distributed in the brain. They have a role in bipolar disorder through $\mathrm{Li}^{+}$ channels in epilepsy by affecting GABA and chloride channels $[19,20]$.

All SLC6 are also referred to as neurotransmitter transporters. These transporters provide regulation of neurotransmitter homeostasis in the central nervous system (CNS) [21]. SLC6 family transporters are known to make a balance between inhibitory neurotransmitters, GABA and glycine, and excitatory neurotransmitter glutamate.

Many subtypes of the SLC7 gene family are expressed in the brain. Particularly, they play an important role in diseases like schizophrenia and Parkinson's disease (PD) 
by influencing the distribution of the amine or amino acid structured neurotransmitter precursor known as L-DOPA $[22,23]$.

The SLC11 (NRAMP) family members catalyze the passage of metal ions like $\mathrm{Fe}^{2+}$ through the cell membrane. $\mathrm{Fe}^{2+}$ is really important for the development of the brain and takes place in many important functions such as neurotransmission and myelination. $\mathrm{Fe}^{2+}$ deficiency during development may have a significant negative impact on brain development and cognition that may lead to a chronic neurological disorder. On the other hand, abnormal levels of $\mathrm{Fe}^{2+}$ have been reported in brain regions in neurodegenerative diseases like PD, Hallervorden-Spatz syndrome, Huntington disease (HD) and Alzheimer disease (AD) $[24,25]$. SLC11A2 mediated $\mathrm{Fe}^{2+}$ transport has been suggested to be involved in neuronal degeneration in $\mathrm{PD}$ and $\mathrm{AD}[26,27]$.

The family of SLC12 chloride carriers contributes to ion currents in various tissues, especially in the brain, kidney and choroid plexus. Seven of the 9 members of this family are well known. $\mathrm{Na}^{+}: \mathrm{K}^{+}: 2 \mathrm{Cl}^{-}$cotransporter 1 (NKCC1) is really important for the function of both central and peripheral nervous systems. The activity of NKCC1 helps to protect the extracellular areas of the brain and the environment of cerebrospinal fluid. NKCC1 expression in neurons is regulated by low expression in mature neurons and high in immature neurons. In the adult peripheral nervous system, NKCC1 is intensely expressed in primary sensory neurons and root ganglia. Although $\mathrm{K}^{+}: \mathrm{Cl}^{-}$cotransporter (KCC) 1, KCC3 and low levels of KCC4 is expressed in the brain, their expression is not limited to the nervous system, as opposed to the neuronal-specific KCC2. KCCs have been associated with sickle cell anemia, cancer growth and as well as neurological diseases. KCC2 expression is high in the hippocampus, cerebellum, and brain stem neurons [28]. Among the members of the SLC superfamily, organic anion transporting polypeptide plays an important role in the transport of both endo-xenobiotics, including numerous drugs throughout the superfamily (OATPs) plasma membranes [29]. It is known that there are eleven OATPs in humans. On this basis, human and rodent OATPs are composed of 6 families (OATP1-6) and each family may have sub-families such as OATP1A, OATP1B, OATP1C. Expressions of OATPs have generally been identified in epithelial or endothelial cells of each organ and some OATPs such as
OATP1C1 specific to the rat brain have limited expression in other specific organs. Commonly expressed OATP2A1, OATP3A1 and OATP4A1 were determined by mRNA in all tissues in human $[29,30]$. OATP1C1, a member of the OATP1 family, is expressed in glial cells throughout the hypothalamus. Moreover, prostaglandin transporter OATP2A1 is one of the ubiquitous OATP which is known to be expressed in neurons, astrocytes, epithelial and endothelial cell layers [30]. OATP3A1, which is localized in neuron and frontal cortex, has the highest expression level in the brain and also found in many tissues. Expression of OATP5A1 and OATP6A1 in the brain were determined with mRNA analysis [29].

Organic cation transporter 3 (OCT3) encoded by SLC22A3 and SCL6A4 encoded serotonin transporter (SERT) has a high and low affinity, respectively during serotonin transport [31]. In SERT knock-out mice, the transcription level of SLC22A3 increased in the hippocampus and no such change was determined in other brain regions [32]. This regulation of SLC22A3 plays an important role in the recruitment of serotonin in the absence of SLC6A4 and may fully obscure the in vivo effect of SERT.

SLC25 proteins that act as carriers of a wide variety of molecules, are the largest SLC family with 46 members (SLC25A1-46) known as mitochondrial carriers [33]. The most of the SLCs are highly expressed in brain regions such as hypothalamus, pituitary, hippocampus, thalamus, amygdala, and brainstem, but are also present intensely in the periphery [34-38]. These proteins have been reported to play a vital role in neuronal signaling for energy production in healthy neurons [39].

In humans, there are two important $\mathrm{Zn}^{2+}$ carrier family known as SLC30 (ZnT) and SLC39 (ZIP) family which provide cellular $\mathrm{Zn}^{2+}$ homeostasis. The SLC39 contains 14 members and they are the transmembrane carriers which pump the extracellular $\mathrm{Zn}^{2+}$ and $\mathrm{Cu}^{2+}$ into the cell. Additionally, recent studies have showed that ZIP family proteins have important role in $\mathrm{Fe}^{2+}$ transport [40]. $\mathrm{Zn}^{2+}$ and $\mathrm{Cu}^{2+}$ play an important role in vital biological processes like growth, development and neuron functions. SLC30A3 transfers $\mathrm{Zn}^{2+}$ to synaptic vesicles in the brain. Interestingly, SLC30A3 expression in the brain is independent of the availability of dietary $Z^{2+}$ and may be important in conservation of brain $\mathrm{Zn}^{2+}$ during $\mathrm{Zn}^{2+}$ deficiency. However, the expression of SLC30A3 decreases with aging, and this process progresses faster in 
patients suffering from neurodegenerative AD [41,42]. Thus, it seems likely that a loss of synaptic accumulation and subsequent release of $\mathrm{Zn}^{2+}$ play a role in $\mathrm{AD}$ pathogenesis [41]. Increased expression of SLC30A1, SLC30A4, and SLC30A6 was observed in AD patients. Chronic perturbation of $\mathrm{Cu}^{2+}$ homeostasis causes neuronal degeneration [43]. Microglia has been shown to upregulate SLC31A1 in response to interferon- $\gamma$ activation. Increased $\mathrm{Cu}^{2+}$ uptake and trafficking by microglia may have a neuroprotective role in $\mathrm{AD}$ [27].

Among the $\mathrm{Mg}^{2+}$ carriers, SLC family 41 (SLC 41) has three members known as A1, A2 and A3. Although SLC41 is distributed in various tissues and organs, it is expressed in brain and provides $\mathrm{Na}^{+} / \mathrm{Mg}^{2+}$ activity. $\mathrm{Na}^{+} / \mathrm{Mg}^{2+}$ activity is obvious in various avian and mammalian cell types like hepatocytes, neurons and glial cells. Degradation or irregularity of $\mathrm{Na}^{+} / \mathrm{Mg}^{2+}$ exchanger may alter the systemic and intracellular $\mathrm{Mg}^{2+}$ homeostasis and participate in the pathogenesis of various diseases related to hypertension, ischemic heart disease, neurodegeneration, inflammation and preeclampsia/eclampsia [27].

\section{DISORDERS}

Given the basic physiological roles of the SLC carriers, it is not surprising that defects in a single carrier lead to a serious disease. The dysfunction of SLCs is associated with countless neurodegenerative disorders (see Table 1).

\section{Alzheimer Disease}

Amyloid- $\beta$ (A $\beta$ ) peptide aggregation or oligomerization, known to be supported in the presence of $\mathrm{Zn}^{2+}$ is one of the reasons affecting the pathogenesis of $\mathrm{AD}$. $\mathrm{Zn}^{2+}$ is transmitted to the brain via SLC39 family carriers. Studies revealed that, the time course expression change of dZip1, an orthologue of human SLC39 family transporter hZIP1 in Drosophila, was recovered in brains of A $\beta 42$ flies when compared with normal control flies. Researchers assume that modulating the expression level of dZip1 may affect the accumulation of $\mathrm{Zn}^{2+}$ in the brain and, accordingly, alter the pathological process of AD [44]. Recently, it has been determined that hippocampusdependent learning and memory functions are not only based on synaptic plasticity of glutamatergic synapses, but also inhibitory GABA-secreting interneurons are required [45]. The closed link between inhibition of learn- ing and memory is also obvious in neurodegenerative disease like Alzheimer's disease mouse model restoring inhibition rescues the associated memory deficits [45]. Divalent cations play a strong role in the pathogenesis of $\mathrm{AD}$ and can also regulate the $\mathrm{A} \beta$ peptide cluster formation. Proton-divalent cation carriers encoded by SLC11A1 and SLC11A2 are expressed in the brain as well as regulate ion homeostasis from endosomal compartments. SLC11A1 also has pleiotropic effects on pro-inflammatory responses that may be important in AD [46].

\section{Dementia}

Lewy body dementia, the second most common neurodegenerative dementia in the elderly, is characterized by Lewy neurites and Lewy bodies which formed by abnormal a-synuclein accumulation in the brainstem, limbic system, and cortical regions [47]. Glutamate transporter SLC family 1, member 2 (GLT1/EAAT2) that is expressed in astrocytes, regulates glutamate levels in synapse and plays an important role in the prevention of excitotoxic neuronal damage in certain neurodegenerative diseases. Modified mRNA and/or protein expression in glutamate transporters have been reported in transgenic models of AD [47]. Neurodegenerative diseases have been suggested to be associated with cellular stress like oxidative stress and endoplasmic reticulum (ER) stress. For instance, the positive immunoreactivity of phosphorylated PERK and elF2a, modulators of the ER stress response pathway, was observed in the substantia nigra of PD patients [7]. Accumulation of ER stress or reactive oxygen species causes cell death of dopaminergic neurons. Although SLC30A10 has been shown to play a protective role against oxidative stress, SLC30A10 and cellular stress are thought to be related to neurodegenerative diseases. The mechanism for the cause of neurodegenerative diseases associated with cellular stress and SLC30A10 has not yet been fully elucidated; besides decreased SLC30A10 levels were determined in the brains of $\mathrm{AD}$ patients. Although the loss of function of SLC30A10 causes Parkinsonism, the role of SLC30A10 in the cellular cause of ER stress that may be associated with PD is unknown. In a study, the SLC30A10 mutation has been shown to cause Parkinsonism, and an autopsy of the AD patient's brain showed a decrease in SLC30A10 [5,16]. On the other hand, oxidative stress or ER stress has been reported to be related to the cause of neurodegenerative disease. In an- 
other study, slc30a10 expression was observed in the cerebral cortex, hippocampus, midbrain, cerebellum and spinal cord of the rat brain. Slc30a10 has also been localized to the dopaminergic neurons of the substantia nigra, glutamatergic neurons of the striatum, and cerebral cortex neurons. Previous studies have demonstrated that the protective role of SLC30A10 against oxidative stress and the relationship between cellular stress and SLC30A10 has not yet been fully elucidated [48].

\section{Amyotrophic Lateral Sclerosis (ALS)}

ALS is the most common adult motor neuron disease leading to muscle paralysis and death within 3-5 years of onset. ALS is a progressive neurodegenerative disease characterized by degeneration of motor neurons in the primary motor cortex, brain stem, and spinal cord [49]. To date, many mechanisms have been described in motor neuron degeneration in ALS. Molecular indicators of glutathione excitotoxicity, impaired axonal transport, oxidative stress, mitochondrial dysfunction, growth factor deficiency, protein aggregation, abnormal RNA metabolism, and apoptosis were observed in the human brain, spinal cord, and transgenic disease models long before the onset of symptoms. Excessive glutamate leading to neuronal degeneration is thought to be one of the pathogenesis of ALS, a fatal neurodegenerative disorder caused by selective death of motor neurons in the brain and spinal cord [50,51]. Riluzol, a drug that is used to treat ALS, inhibits the activation of postsynaptic neurons that prevent glutamate release and reduce glutamate-induced sodium ecototoxicity [50]. Loss of EAAT1 was observed in patients with ALS. Riluzole was found to increase the transport activity of SLC1A3, which takes extracellular glutamate from the synapses and thus reduces glutamate levels in the synaptic cleft $[52,53]$. In another study, riluzole has been shown to stimulate glutamate uptake by increasing the level of SLC1A1 excitatory amino acid carrier in astroglial cells. Similar to EAAT1, EAAT2, the major glutamate carrier in astrocytes, has been reported to reduce the level of glutamate in the synaptic cleft, thereby alleviating excitotoxicity. The neurodegenerative diseases that may benefit from the upregulated EAAT2 function include epilepsy, stroke, and neurotrauma, as well as AD, ALS and PD. All of these diseases have been associated with a decrease in EAAT2 protein expression levels [52-55]. A decrease in glutamate transporter activity has been reported due to decreased GLT1 (EAAT2) isoform in motor and sensory cortex in patients with sporadic ALS [9]. A decrease in glutamate transporter activity has been reported due to decreased GLT1 (EAAT2) isoform in motor and sensory cortex in patients with sporadic ALS [9]. For these reasons, the development of a drug that enhances the activity of EAAT2 represents a promising approach to the development of a CNS. According to the mRNA analysis, the previous studies show that the expression of EAAT2 decreased in the spinal cord, motor cortex in ALS's patients $[56,57]$. The SLC25A20, a member of the large mitochondrial carrier family, catalyzes transport through the inner mitochondrial membrane. The production of ATP, calcium homeostasis and the regulation of mitochondria-associated apoptosis are reported in ALS. Abnormalities in the morphology and biochemistry of the cortex, spinal cord and muscles were observed in patients with ALS [58-60].

\section{Huntington Disease}

HD is a deadly neurodegenerative disease that cannot be treated today. Although HD is classically regarded as a motor disorder, it is also characterized by progressive motor coordination disorder and involuntary movements resulting from neurodegeneration of the striatum. HD patients experience cognitive and behavioral disorders such as learning and memory, due to impairment of cortex and hippocampus many years before the onset of motor symptoms. Additionally, similar symptoms are observed in HD mouse models [61]. While HD patients show hippocampal memory and learning deficits, changes in excitatory synaptic plasticity and spatial cognition in the hippocampus have been reported in HD mouse models [62-64].

Hippocampus excitatory synaptic plasticity changes and degeneration in spatial cognition are reported to occur in HD mouse models [65-69]. Proteomic studies have shown that the gene encoding the KCC2, slc12A5, is highly rich in the Huntington protein ( $\mathrm{Htt}$ ) proteome $[25,26]$. In the mouse study, by using isoform-specific amplification of slc12a5 (KCC2) and slc12a2 (NKCC1), it has been found out that KCC2 protein expression decreased in the hippocampus as it was affected by $\mathrm{Htt}$ [61].

\section{Parkinson's Disease}

SLC41A1, which has recently been identified as a part of a new PD susceptibility locus named PARK16, has 
been reported in the pathophysiology of PD, preeclampsia, and nephronophthisis-associated ciliopathies. After that, rare PD-associated coding variants of SLC41A1, ie p.A350V, p.L146G, p.P480P and c.552 + 50G > A, were identified [44]. Studies have shown that nigrostriatal dopamine loss is important in the distinctive features of PD. SLC6A3 is known to play an important role in dopamine reuptake in striatal [70]. Allelic variants in SLC6A3 are located in PD by modulating gene expression and may increase the risk of PD by interacting with the occupational pesticide. SLC6A3/DAT1 genotype has also been found to have a significant effect on fronto-striatal activation and performance in PD. Therefore, SLC6A3 is thought to be associated with PD development by modulating the metabolism of dopamine [71]. A number of different evidences suggest that the overlapping clinical, genetic, and pathological features of PD, MSA and ALS may be caused by a common potential pathogenic pathway. Firstly, epidemiological studies have indicated that some patients with ALS have parkinsonian symptoms and also the increase in the number of PD patients thought to enhance the risk of developing ALS. Moreover, as ALS and MSA show clinical overlaps, all other evidence suggests that all these diseases occur with the combination of abnormal and improperly folded proteins. Disruption of SLC40A1 mediated $\mathrm{Fe}^{2+}$ flow from neurons is thought to be one of the pathogenesis of PD [72-74]. Disruption of SLC40A1mediated $\mathrm{Fe}^{2+}$ flow from neurons may also contribute to the pathogenesis of PD [75].

\section{Depression}

Drugs used to treat depression can be classified according to their possible targets. For example, monoamine reuptake inhibitors containing serotonin-selective reuptake inhibitors and noradrenaline reuptake inhibitors inhibit neurotransmitter carriers. Over the past few decades, the development of new antidepressants has been moved from "chance of discovery" to single-targeted strategies and then to multiple target strategies. Several carriers in the SLC6 family have important roles in taking monoamines into the synapses of the CNS. Although they all show overlapping substrate specificity, these include NET (SLC6A2), DAT (SLC6A3), and SERT (SLC6A4), all of which are carriers of noradrenaline, dopamine, and serotonin (also known as 5-hydroxytryptamine). Drug-mediated inhibition of these carriers reduces the clearance of monoamine neurotransmitters from the synapse and thus increases the residence time in the synaptic cleft. As a result, increased concentrations of monoamines in the synaptic cleft increase receptor invasion, leading to increased activation of ligand-gated ion channels and modulation of G-protein-bound receptor signaling. However, the mechanisms by which such drugs ultimately exert antidepressant effects are not yet completely clear $[21,76]$. Glycine has important roles in neuronal inhibition and stimulation in the CNS. It acts as an inhibitor neurotransmitter by activating ionotropic glycine receptors, providing chloride ions to hyperpolarize the postsynaptic membrane. Glycine also binds to excitatory NMDA receptors to provide receptor activation with glutamate. Glycine carriers such as GLYT1 (also known as SLC6A9) and GLYT2 (also known as SLC6A5) on neurons, astrocytes, and glial cells regulate extracellular glycine levels in the brain and thereby regulate NMDA receptor activity [77].

SLC6A15, a neutral amino acid transporter expressed in neurons, is recommended as a candidate gene for major depression and stress vulnerability with glutamate content, a key neurotransmitter regulating stress response in the hippocampus [78]. A single nucleotide polymorphism in this gene shows all the markers of altered volume, glutamate levels, and hypothalamus-pituitaryadrenal axis activity and major depression [78].

In a study of chronic social stress where a conventional slc6a15 knock-out mouse line and a virus-mediated hippocampal slc6a15 overexpression mice were used, both slc-knock-out mice and a virus-mediated hippocampal slc6a15 overexpression mice were reported to have lower anxiety and depressive behaviors compared to stressed wild-type offspring, after chronic social stress. These findings suggest that the deletion of slc6a15 changes the HPA axis activation following chronic social stress and reduces the negative behavioral consequences of chronic social stress. In addition, the expression levels of GluR1 in hippocampus, particularly in dentate gyrus, were reported to be significantly affected by levels of slc6a15. The results of the study showed that slc6a15 levels affect HPA axis activation under chronic stress conditions, regulating anxiety and depressive behaviors and affecting GluR1 expression in hippocampus [78]. 


\section{Post-Traumatic Stress Disorder (PTSD)}

PTSD is a complex disorder characterized by three symptom clusters including re-experiencing, avoidance, and hyperarousal. SLC6A3 (also known as DAT1 or DAT) and it is a biologically relevant candidate gene for PTSD. SLC6A3 encodes a dopamine transporter, a member of the sodium- and chloride-dependent neurotransmitter transporter family, which plays a key role in the regulation of dopaminergic neurotransmission by removing dopamine from the synaptic cleft [79]. The role of dopamine in the etiology of PTSD is supported by increased urine and plasma dopamine levels. This shows a significant correlation between dopamine concentration and severity of PTSD symptoms. The complexity of the relationship between SLC6A3 and PTSD may be related, not only to genetic but also to the evidence that epigenetic factors constitute the risk of mental illness. Epigenetic disorder plays a role in the pathogenesis of various psychiatric disorders such as depression, schizophrenia, and PTSD. The study investigating how genetic and epigenetic, molecular variation in the SLC6A3 locus affect the risk of PTSD, it has been reported that SLC6A3 39UTR VNTR polymorphism significantly increased the lifetime risk of PTSD. It has also been shown that participants with high DNA methylation provide preventive new evidence for interaction with genetic and epigenetic variation affecting PTSD risk, which significantly increases the risk of the disease. The results of the study support the 9R allele of SLC6A3 39UTR VNTR polymorphism as a risk allele for PTSD compared to homozygous 10R genotype in PTSD [80].

\section{Schizophrenia}

Glycine has an important role in neuronal inhibition and stimulation in CNS. Glycine binds to excitatory NMDA receptors to provide receptor activation with glutamate. Glycine carriers such as GLYT1 (also known as SLC6A9) and GLYT2 (also known as SLC6A5) on neurons, astrocytes, and glial cells regulate levels of extracellular glycine in the brain and thereby regulate NMDA receptor activity. According to the glutamate hypothesis of schizophrenia, the symptoms of the disease are caused by insufficient glutamatergic (NMDA) signaling and therefore GLYT1 inhibitors have been developed to increase the NMDA signal in this disorder to inhibit glycine reuptake in NMDA receptors and to increase glycine levels [2].

\section{Epilepsy}

Epilepsy is one of the most common neurological disorders in the population up to $1 \%$. It is a complex genetic disease, and many different gene families are actively being investigated as a potential response to antiepileptic drugs. Decreased KCC2 expression in mouse models of intractable epilepsy and in human patients with temporal lobe epilepsy is additional evidence for its role in the regulation of neuronal excitability [28]. In a study, it has been shown that the synaptic protein SLC10A4 affects the sensitivity to cholinergic chemo-convulsant and the absence of SLC10A4 induces the altered function of neural networks and possibly epileptic vulnerability $[81,82]$.

\section{CONCLUSION}

In this review, it has been emphasized that SLC proteins are of great importance in the elucidation of neurodegenerative disorder mechanism due to their important role in the synaptic regulation of the neurotransmitters. Therefore, this review will also contribute to the regulation of existing treatments and the creation of new treatment options, with the non-radical treatment of SLC proteins.

\section{- Conflicts of Interest}

No potential conflict of interest relevant to this article was reported.

\section{Author Contributions}

Conceptualization: Asli Aykaç, Ahmet Özer Şehirli. Data acquisition: Asli Aykaç, Ahmet Özer Şehirli. Formal analysis: Asli Aykaç, Ahmet Özer Şehirli. Supervision: Asli Aykaç, Ahmet Özer Şehirli. Writing-original draft: Asli Aykaç, Ahmet Özer Şehirli. Writing-review \& editing: Asli Aykaç, Ahmet Özer Şehirli.

\section{ORCID}

Asli Aykaç

https://orcid.org/0000-0002-4885-5070

Ahmet Özer Şehirli https://orcid.org/0000-0002-8075-3672

\section{REFERENCES}

1. Hediger MA, Clémençon B, Burrier RE, Bruford EA. The ABCS of membrane transporters in health and disease (SLC series): introduction. Mol Aspects Med 2012;34:95-107.

2. Lin L, Yee SW, Kim RB, Giacomini KM. SLC transporters as 
therapeutic targets: emerging opportunities. Nat Rev Drug Discov 2015; 14:543-560.

3. Bai X, Moraes TF, Reithmeier RAF. Structural biology of solute carrier (SLC) membrane transport proteins. Mol Membr Biol 2018;13:1-32.

4. Simpson IA, Carruthers A, Vannucci SJ. Supply and demand in cerebral energy metabolism: the role of nutrient transporters. J Cereb Blood Flow Metab 2007;27:1766-1791.

5. Brunton LL, Parker KL, Buxton ILO. Goodman \& Gilman's: the pharmacological basis of therapeutics. New York:McGrawHill;2008.

6. Mueckler M, Thorens B. The SLC2 (GLUT) family of membrane transporters. Mol Aspects Med 2013;34:121-138.

7. Wright EM. Glucose transport families SLC5 and SLC50. Mol Aspects Med 2013;34:183-196.

8. Kanai Y, Hediger MA. Primary structure and functional characterization of a high-affinity g/utamate transporter. Nature 1992;360:467-471.

9. Kanai Y, Hediger MA. The glutamate/neutral amino acid transporter family SLC1: molecular, physiological and pharmacological aspects. Pflugers Arch 2004;447:469-479.

10. Xu Y, Cao B, Chen Y, Ou R, Wei Q, Yang J, et al. SLC1A2 rs3794087 are associated with susceptibility to Parkinson's disease, but not essential tremor, amyotrophic lateral sclerosis or multiple system atrophy in a Chinese population. J Neurol Sci 2016;365:96-100.

11. Tanaka K, Watase K, Manabe T, Yamada K, Watanabe M, Takahashi $\mathrm{K}$, et al. Epilepsy and exacerbation of brain injury in mice lacking the glutamate transporter GLT-1. Science 1997;276:1699-1702.

12. Arriza JL, Kavanaugh MP, Fairman WA, Wu YN, Murdoch $\mathrm{GH}$, North RA, et al. Cloning and expression of a human neutral amino acid transporter with structural similarity to the g/utamate transporter gene family. J Biol Chem 1993;268:1532915332.

13. Shafqat S, Tamarappoo BK, Kilberg MS, Puranam RS, McNamara JO, Guadaño-Ferraz A, et al. Cloning and expression of a novel $\mathrm{Na}^{+}$-dependent neutral amino acid transporter structurally related to mammalian $\mathrm{Na}^{+} / g$ lutamate cotransporters. J Biol Chem 1993;268:15351-15355.

14. Sakai K, Shimizu H, Koike T, Furuya S, Watanabe M. Neutral amino acid transporter ASCT1 is preferentially expressed in L-Ser-synthetic/storing glial cells in the mouse brain with transient expression in developing capillaries. J Neurosci 2003; 23:550-560.

15. Utsunomiya-Tate N, Endou H, Kanai Y. Cloning and functional characterization of a system ASC-like $\mathrm{Na}^{+}$-dependent neutral amino acid transporter. J Biol Chem 1996;271:1488314890.

16. Bröer A, Wagner C, Lang F, Bröer S. Neutral amino acid transporter ASCT2 displays substrate-induced $\mathrm{Na}^{+}$exchange and a substrate-gated anion conductance. Biochem J 2000;346 Pt 3:705-710.
17. Fairman WA, Vandenberg RJ, Arriza JL, Kavanaugh MP, Amara SG. An excitatory amino-acid transporter with properties of a ligand-gated chloride channel. Nature 1995;375: 599-603.

18. Nagao S, Kwak S, Kanazawa I. EAAT4, a glutamate transporter with properties of a chloride channel, is predominantly localized in Purkinje cell dendrites, and forms parasagittal compartments in rat cerebellum. Neuroscience 1997;78:929-933.

19. Romero MF, Chen AP, Parker MD, Boron WF. The SLC4 family of bicarbonate $\left(\mathrm{HCO}_{3}{ }^{-}\right)$transporters. Mol Aspects Med 2013;34:159-182.

20. Alka K, Casey JR. Bicarbonate transport in health and disease. IUBMB Life 2014;66:596-615.

21. Kristensen AS, Andersen J, Jørgensen TN, Sørensen L, Eriksen J, Loland CJ, et al. SLC6 neurotransmitter transporters: structure, function, and regulation. Pharmacol Rev 2011;63:585640.

22. Fotiadis D, Kanai Y, Palacín M. The SLC3 and SLC7 families of amino acid transporters. Mol Aspects Med 2013;34:139-158.

23. Scalise $M$, Galluccio $M$, Console L, Pochini L, Indiveri C. The human SLC7A5 (LAT1): the intriguing histidine/large neutral amino acid transporter and its relevance to human health. Front Chem 2018;6:243.

24. Berg D, Gerlach M, Youdim MB, Double KL, Zecca L, Riederer $\mathrm{P}$, et al. Brain iron pathways and their relevance to Parkinson's disease. J Neurochem 2001;79:225-236.

25. Thomas M, Jankovic J. Neurodegenerative disease and iron storage in the brain. Curr Opin Neurol 2004;17:437-442.

26. Salazar J, Mena N, Hunot S, Prigent A, Alvarez-Fischer D, Arredondo M, et al. Divalent metal transporter 1 (DMT1) contributes to neurodegeneration in animal models of Parkinson's disease. Proc Natl Acad Sci U S A 2008;105: 18578-18583.

27. Zheng Z, White C, Lee J, Peterson TS, Bush Al, Sun GY, et al. Altered microglial copper homeostasis in a mouse model of Alzheimer's disease. J Neurochem 2010;114:1630-1638.

28. Arroyo JP, Kahle KT, Gamba G. The SLC12 family of electroneutral cation-coupled chloride cotransporters. Mol Aspects Med 2013;34:288-298.

29. Hagenbuch B, Stieger B. The SLCO (former SLC21) superfamily of transporters. Mol Aspects Med 2013;34:396-412.

30. Roth M, Obaidat A, Hagenbuch B. OATPS, OATs and OCTs: the organic anion and cation transporters of the SLCO and SLC22A gene superfamilies. Br J Pharmacol 2012;165:12601287.

31. Vallon V, Eraly SA, Rao SR, Gerasimova M, Rose M, Nagle M, et al. A role for the organic anion transporter OAT3 in renal creatinine secretion in mice. Am J Physiol Renal Physiol 2012;302:F1293-F1299.

32. Schmitt A, Mössner R, Gossmann A, Fischer IG, Gorboulev V, Murphy DL, et al. Organic cation transporter capable of transporting serotonin is up-regulated in serotonin transporter-deficient mice. J Neurosci Res 2003;71:701-709. 
33. Haitina T, Lindblom J, Renström T, Fredriksson R. Fourteen novel human members of mitochondrial solute carrier family 25 (SLC25) widely expressed in the central nervous system. Genomics 2006;88:779-790.

34. Mao W, Yu XX, Zhong A, Li W, Brush J, Sherwood SW, et al. UCP4, a novel brain-specific mitochondrial protein that reduces membrane potential in mammalian cells. FEBS Lett 1999;443:326-330.

35. Sanchis D, Fleury C, Chomiki N, Goubern M, Huang Q, Neverova $\mathrm{M}$, et al. BMCP1, a novel mitochondrial carrier with high expression in the central nervous system of humans and rodents, and respiration uncoupling activity in recombinant yeast. J Biol Chem 1998;273:34611-34615.

36. Richard D, Clavel S, Huang Q, Sanchis D, Ricquier D. Uncoupling protein 2 in the brain: distribution and function. Biochem Soc Trans 2001;29(Pt 6):812-817.

37. Arsenijevic D, Onuma H, Pecqueur C, Raimbault S, Manning BS, Miroux B, et al. Disruption of the uncoupling protein-2 gene in mice reveals a role in immunity and reactive oxygen species production. Nat Genet 2006;26:435-439.

38. Kim-Han JS, Reichert SA, Quick KL, Dugan LL. BMCP1: a mitochondrial uncoupling protein in neurons which regulates mitochondrial function and oxidant production. J Neurochem 2001;79:658-668.

39. Li Z, Okamoto K, Hayashi Y, Sheng M. The importance of dendritic mitochondria in the morphogenesis and plasticity of spines and synapses. Cell 2004;119:873-887.

40. Schweigel-Röntgen M. The families of zinc (SLC3O and SLC39) and copper (SLC31) transporters. Curr Top Membr 2004;73:321-355.

41. Adlard PA, Parncutt JM, Finkelstein DI, Bush Al. Cognitive loss in zinc transporter-3 knock-out mice: a phenocopy for the synaptic and memory deficits of Alzheimer's disease? I Neurosci 2010;30:1631-1636.

42. Lovell MA, Smith JL, Xiong S, Markesbery WR. Alterations in zinc transporter protein-1 (ZnT-1) in the brain of subjects with mild cognitive impairment, early, and late-stage Alzheimer's disease. Neurotox Res 2005; 7:265-271.

43. Nevitt T, Ohrvik H, Thiele DJ. Charting the travels of copper in eukaryotes from yeast to mammals. Biochim Biophys Acta 2012;1823:1580-1593.

44. Schweigel-Röntgen M, Kolisek M. SLC41 transporters--molecular identification and functional role. Curr Top Membr 2014;73: 383-410.

45. Lang M, Wang L, Fan Q, Xiao G, Wang X, Zhong Y, et al. Genetic inhibition of solute-linked carrier 39 family transporter 1 ameliorates a $\beta$ pathology in a Drosophila model of Alzheimer's disease. PLoS Genet 2012;8:e1002683.

46. Donato F, Rompani SB, Caroni P. Parvalbumin-expressing basket-cell network plasticity induced by experience regulates adult learning. Nature 2013;504:272-276.

47. Garcia-Esparcia P, Diaz-Lucena D, Ainciburu M, TorrejónEscribano B, Carmona M, Llorens F, et al. Glutamate trans- porter GLT1 expression in Alzheimer disease and dementia with Lewy bodies. Front Aging Neurosci 2018;10:112.

48. Go S, Kurita H, Yokoo K, Inden M, Kambe T, Hozumi I. Protective function of SLC3OA10 induced via PERK-ATF4 pathway against 1-methyl-4-phenylpyridinium. Biochem Biophys Res Commun 2017;490:1307-1313.

49. Jamieson SE, White JK, Howson JM, Pask R, Smith AN, Brayne $\mathrm{C}$, et al. Candidate gene association study of solute carrier family 11a members 1 (SLC11A1) and 2 (SLC11A2) genes in Alzheimer's disease. Neurosci Lett 2005;374:124-128.

50. Häggmark A, Mikus M, Mohsenchian A, Hong MG, Forsström B, Gajewska B, et al. Plasma profiling reveals three proteins associated to amyotrophic lateral sclerosis. Ann Clin Transl Neurol 2014;1:544-553.

51. Paez-Colasante X, Figueroa-Romero C, Sakowski SA, Goutman SA, Feldman EL. Amyotrophic lateral sclerosis: mechanisms and therapeutics in the epigenomic era. Nat Rev Neurol 2015;11:266-279.

52. Carbone M, Duty S, Rattray M. Riluzole elevates GL T-1 activity and levels in striatal astrocytes. Neurochem Int 2012;60: 31-38.

53. Dall'Igna OP, Bobermin LD, Souza DO, Quincozes-Santos A. Riluzole increases g/utamate uptake by cultured C6 astroglial cells. Int J Dev Neurosci 2013;31:482-486.

54. Woltjer RL, Duerson K, Fullmer JM, Mookherjee P, Ryan AM, Montine TJ, et al. Aberrant detergent-insoluble excitatory amino acid transporter 2 accumulates in Alzheimer disease. J Neuropathol Exp Neurol 2010;69:667-676.

55. Guo H, Lai L, Butchbach ME, Stockinger MP, Shan X, Bishop $\mathrm{GA}$, et al. Increased expression of the glial glutamate transporter EAAT2 modulates excitotoxicity and delays the onset but not the outcome of ALS in mice. Hum Mol Genet 2003; 12:2519-2532.

56. Rothstein JD, Van Kammen M, Levey Al, Martin LJ, Kuncl RW. Selective loss of glial glutamate transporter GLT-1 in amyotrophic lateral sclerosis. Ann Neurol 1995;38:73-84.

57. Karki P, Smith K, Johnson Jr J, Aschner M, Lee ES. Genetic dys-regulation of astrocytic glutamate transporter EAAT2 and its implications in neurological disorders and manganese toxicity. Neurochem Res 2015;40:380-388.

58. Kong Q, Chang LC, Takahashi K, Liu Q, Schulte DA, Lai L, et al. Small-molecule activator of glutamate transporter EAAT2 translation provides neuroprotection. J Clin Invest 2014;124: 1255-1267.

59. Sasaki S, Iwata M. Ultrastructural change of synapses of Betz cells in patients with amyotrophic lateral sclerosis. Neurosci Lett 1999;268:29-32.

60. Wong PC, Pardo CA, Borchelt DR, Lee MK, Copeland NG, Jenkins NA, et al. An adverse property of a familial ALS-linked SOD1 mutation causes motor neuron disease characterized by vacuolar degeneration of mitochondria. Neuron 1995;14: 1105-1116.

61. Dargaei Z, Bang JY, Mahadevan V, Khademullah CS, Bedard 
S, Parfitt GM, et al. Restoring GABAergic inhibition rescues memory deficits in a Huntington's disease mouse model. Proc Natl Acad Sci U S A 2018;115:E1618-E1626.

62. Begeti F, Schwab LC, Mason SL, Barker RA. Hippocampal dysfunction defines disease onset in Huntington's disease. J Neurol Neurosurg Psychiatry 2016;87:975-981.

63. Lemiere J, Decruyenaere M, Evers-Kiebooms G, Vandenbussche E, Dom R. Cognitive changes in patients with Huntington's disease $(H D)$ and asymptomatic carriers of the HD mutation--a longitudinal follow-up study. J Neurol 2004;251:935942.

64. Paulsen JS. Cognitive impairment in Huntington disease: diagnosis and treatment. Curr Neurol Neurosci Rep 2011;11: 474-483.

65. Usdin MT, Shelbourne PF, Myers RM, Madison DV. Impaired synaptic plasticity in mice carrying the Huntington's disease mutation. Hum Mol Genet 1999;8:839-846.

66. Lynch G, Kramar EA, Rex CS, Jia Y, Chappas D, Gall CM, et al. Brain-derived neurotrophic factor restores synaptic plasticity in a knock-in mouse model of Huntington's disease. J Neurosci 2007;27:4424-4434.

67. Simmons DA, Rex CS, Palmer L, Pandyarajan V, Fedulov V, Gall $\mathrm{CM}$, et al. Up-regulating BDNF with an ampakine rescues synaptic plasticity and memory in Huntington's disease knockin mice. Proc Natl Acad Sci U S A 2009;106:49064911.

68. Kolodziejczyk K, Parsons MP, Southwell AL, Hayden MR, Raymond LA. Striatal synaptic dysfunction and hippocampal plasticity deficits in the Hu97/18 mouse model of Huntington disease. PLoS One 2014;9:e94562.

69. Lione LA, Carter RJ, Hunt MJ, Bates GP, Morton AJ, Dunnett $\mathrm{SB}$. Selective discrimination learning impairments in mice expressing the human Huntington's disease mutation. J Neurosci 1999;19:10428-10437.

70. Habak C, Noreau A, Nagano-Saito A, Mejía-Constaín B, Degroot C, Strafella AP, et al. Dopamine transporter SLC6A3 genotype affects cortico-striatal activity of set-shifts in Parkinson's disease. Brain 2014;137(Pt 11):3025-3035.

71. Li J, Sun Y, Chen J. Identification of critical genes and miRNAs associated with the development of Parkinson's disease. J Mol
Neurosci 2018;65:527-535.

72. Majoor-Krakauer D, Ottman R, Johnson WG, Rowland LP. Familial aggregation of amyotrophic lateral sclerosis, dementia, and Parkinson's disease: evidence of shared genetic susceptibility. Neurology 1994;44:1872-1877.

73. Gilbert RM, Fahn S, Mitsumoto H, Rowland LP. Parkinsonism and motor neuron diseases: twenty-seven patients with diverse overlap syndromes. Mov Disord 2010;25:1868-1875.

74. Gouras GK. Convergence of synapses, endosomes, and prions in the biology of neurodegenerative diseases. Int I Cell Biol 2013;2013:e141083.

75. Montalbetti N, Simonin A, Kovacs G, Hediger MA. Mammalian iron transporters: families SLC11 and SLC4O. Mol Aspects Med 2013;34:270-287.

76. Haase J, Brown E. Integrating the monoamine, neurotrophin and cytokine hypotheses of depression--a central role for the serotonin transporter? Pharmacol Ther 2015;147:1-11.

77. Harvey RJ, Yee BK. Glycine transporters as novel therapeutic targets in schizophrenia, alcohol dependence and pain. Nat Rev Drug Discov 2013;12:866-885.

78. Santarelli S, Namendorf C, Anderzhanova E, Gerlach T, Bedenk B, Kaltwasser S, et al. The amino acid transporter SLC6A15 is a regulator of hippocampal neurochemistry and behavior. J Psychiatr Res 2015;68:261-269.

79. Li L, Bao Y, He S, Wang G, Guan Y, Ma D, et al. The association between genetic variants in the dopaminergic system and posttraumatic stress disorder: a meta-analysis. Medicine (Baltimore) 2016;95:e3074.

80. Chang SC, Koenen KC, Galea S, Aiello AE, Soliven R, Wildman $\mathrm{DE}$, et al. Molecular variation at the SLC6A3 locus predicts lifetime risk of PTSD in the Detroit Neighborhood Health Study. PLoS One 2012; 7:e39184.

81. Zelano J, Mikulovic S, Patra K, Kühnemund M, Larhammar M, Emilsson L, et al. The synaptic protein encoded by the gene Slc10A4 suppresses epileptiform activity and regulates sensitivity to cholinergic chemoconvulsants. Exp Neurol 2013; 239:73-81.

82. Bröer S, Gether U. The solute carrier 6 family of transporters. Br J Pharmacol 2012;167:256-278. 